\title{
The composition of acid/oil interface in acid oil emulsions
}

\author{
Yulia M. Ganeeva ${ }^{1} \cdot$ Tatiana N. Yusupova $^{1}$ - Ekaterina E. Barskaya ${ }^{1}$ - Alina Kh. Valiullova ${ }^{1}$ - Ekaterina S. Okhotnikova ${ }^{1}$. \\ Vladimir I. Morozov' ${ }^{1}$ Lucia F. Davletshina ${ }^{2}$
}

Received: 21 November 2019 / Published online: 23 April 2020

(c) The Author(s) 2020

\begin{abstract}
In well stimulation treatments using hydrochloric acid, undesirable water-in-oil emulsion and acid sludge may produce and then cause operational problems in oil field development. The processes intensify in the presence of Fe(III), which are from the corroded surfaces of field equipment and/or iron-bearing minerals of the oil reservoir. In order to understand the reasons of the stability of acid emulsions, acid emulsions were prepared by mixing crude oil emulsion with $15 \%$ hydrochloric acid solutions with and without Fe(III) and then separated into free and upper (water free) and intermediate (with water) layers. It is assumed that the oil phase of the free and upper layers contains the compounds which do not participate in the formation of acid emulsions, and the oil phase of the intermediate layers contains components involved in the formation of oil/ acid interface. The composition of the oil phase of each layer of the emulsions was studied. It is found that the asphaltenes with a high content of sulfur, oxygen and metals as well the flocculated material of protonated non-polar oil components are concentrated at the oil/acid interface. In addition to the above, in the presence of $\mathrm{Fe}$ (III) the $\mathrm{Fe}$ (III)-based complexes with polar groups of asphaltenes are formed at the acid/oil interface, contributing to the formation of armor films which enhance the emulsion stability.
\end{abstract}

Keywords Acid emulsions · Ferric cations · Acid/oil interface · Asphaltenes · Resins · Waxes · Oil paramagnetic particles · $\mathrm{Fe}(\mathrm{III})$-based complexes

\section{Introduction}

During well operations, reservoir porosity and permeability of bottomhole rock deteriorate as a result of clay swelling, mineral scaling, asphaltene and wax deposition, formation of high viscosity water-in-oil emulsions, etc. To improve wellto-reservoir connectivity and restore rock permeability in the bottomhole formation zone, well stimulation treatments with various acids are used. However, the use of acid is accompanied by a number of negative consequences (Fredd and Fogler 1998). During acid treatment there is an interaction of

Edited by Yan-Hua Sun

Yulia M. Ganeeva yuyand@yandex.ru

1 Arbuzov Institute of Organic and Physical Chemistry, FRC Kazan Scientific Center, Russian Academy of Sciences, Arbuzov str. 8, Kazan 420088, Russian Federation

2 Gubkin Russian State University of Oil and Gas (National Research University), Leninsky Prospekt 65, Moscow 119991, Russian Federation acid with the rock, in which significant quantities of soluble and insoluble inorganic products capable of precipitating and clogging the reservoir pores can form, thereby reducing the rate of production wells and the intake capacity of injection wells. In addition, a serious danger is also posed by the products of the direct interaction of acidic formulations with petroleum fluid. The interaction of the acid with crude oil is accompanied by the formation of stable water-in-oil emulsions and/or asphaltic sludge. The formation of waterin-oil emulsion and asphaltic sludge may cause operational problems in field development such as permeability reduction, increase in fluid viscosity and formation wettability alteration from water wet to oil wet (Shirazi et al. 2019).

The operational effective factors affecting the acid oil emulsion and sludge formation are compiled by Shirazi et al. (2019) and are: acid type and strength, additives, temperature, iron concentration particularly ferric, exposure time, mixing rate and acid mixture ratio. In addition, it is shown that such crude oil properties as acid number and base number, hydrogen sulfide content, crude oil sample aging, density, viscosity, acid-oil interfacial tension and iron 
adsorption capability from the acid phase also affect emulsion and sludge formation.

It is generally believed that the formation of stable waterin-oil emulsion is caused by the adsorption at the oil/water interface the surface-active compounds, such as asphaltenes, resins and naphthenic acids present in the oil.

As to asphaltenes, there is evidence that only the most self-associated (least soluble) asphaltenes with increased aromaticity (Rocha et al. 2018), decreased alkyl side chain lengths, and reduced chain branching (Khadim and Sarbar 1999), act as emulsion stabilizer. Yang et al. (2014, 2015) suggested that the most interfacial active asphaltene (IAA) subfraction having higher molecular weight and higher contents of heteroatoms, oxygen-containing functional groups, in particular the high-polarity sulfoxide groups (Qjao et al. 2017), concentrates at the oil/water interface. It is assumed that IAA molecules self-associate in solvent, and as supramolecular structures with a porous network are concentrated at the oil/water interface. Rojas-Ruiz and Orrego-Ruiz (2018) showed that the ratio between oxygenand non-oxygen containing compounds may determine the surfactant character of asphaltenes at the oil/water interface. Muller et al. (2009) detected that asphaltenes together with high amounts of distinctive mono- and diprotic naphthenic acids and sulfur- and oxygen-containing aromatic molecules predominate in interfacial material.

Resins, although quite surface-active, have not been found to stabilize water-in-oil emulsions significantly. However, resins tend to solvate asphaltene aggregates and lower their surface activity, thus decreasing the emulsion stability (Abdel-Raouf 2012; Spiecker et al. 2003; Sedghi and Goual 2009; McLean and Kilpatrick 1997). Naphthenic acids have an amphiphilic structure and at certain conditions they can either enhance the stabilization of emulsions (Brandal and Sjoblom 2005) or "soften" the rigid interface and promote flocculation (Gao et al. 2010).

An enhanced activity of oxygen- and nitrogen-containing compounds in stabilization of emulsions of highly paraffinic crude oils was found by Pereira et al. (2014).

As mentioned before, it is generally assumed that sludge is asphaltenic in nature. However, crude oils that contain little or no asphaltenes can produce sludge too (Shirazi et al. 2019; Rietjens 1997). This type of sludge is referred to as non-asphaltenic sludge. Rietjens (1997) showed that all Bronsted acids ( $\mathrm{HCl}$, acetic, etc.) have a similar effect on sludge formation, the amount of sludge being a function of the acidity function $H_{\mathrm{o}}$ in the water phase only, the total amount of phase-transported acid in oil is proportional to the base content of the crude oil (Rietjens and Haasterecht 2003).

The role of $\mathrm{Fe}(\mathrm{III})$ in stable emulsion and sludge formation is not yet fully understood. However, it is well known that these processes are greatly enhanced in the presence of ferric cations, the sources of which are the corroded surfaces of field equipment and iron-bearing minerals of the oil reservoir. On the one hand, it is assumed (O'Neil et al. 2015) that $\mathrm{Fe}(\mathrm{III})$, especially in form of the complex $\mathrm{HFeCl}_{4}$ facilitates acid transfer to the oil phase, increasing the acid concentration in the oil; this assumption is confirmed by an insignificant iron content in the precipitate (sludge) and by similar chemical structure of precipitates formed with and without participation of iron. On the other hand, it has been shown (Antipenko et al. 1994) that $\mathrm{Fe}(\mathrm{III})$ participates in complexation with the aromatic cores of asphaltenes, causing them to flocculate into large asphaltene clusters that are unstable to deposition. The centers of localization of the bonding of iron ions with the organic matrix in these complexes are heteroatomic units of the molecules, free stable radicals, and vanadyl ions.

It should be noted that the presence of other solids like crystalline waxes, clays, corrosion products and mineral scales may also lead to the formation of very stable oil-water emulsions and sludge (Hadabi et al. 2016; Poindexter and Marsh 2009; Sullivan and Kilpatrick 2002). An increase in solid concentrations leads to an increase in the emulsion stability while the decrease in solid sizes leads to a more stable emulsion. The irreversible adsorption of solids has a major consequence on the long-term stability (Umar et al. 2018). Besides, the variety of acid additives (anti-sludging agents, corrosion inhibitors, and iron reducing agents) is used to prevent the sludging and emulsion forming problem. However, their effectiveness is limited by the need to obtain a compatible combination of additives and a lack of understanding of the complex chemistries involved in the precipitation reactions (Fredd and Fogler 1998).

Scientific approach to the development of the emulsion destruction technologies is based on an in-depth study of the composition of interfacial layers of emulsions depending on the natural emulsifiers-asphaltenes, resins, waxes.

The aim of this work is to identify the effect of hydrochloric acid as well as additive of ferric chloride solution on the formation of stable oil emulsions. For this purpose, the features of redistribution of asphaltenes and waxes (which are the natural interfacial active components responsible for emulsion stability) in acid emulsions with and without ferric cations are studied. The conclusions are based on the assumption that the oil phase of the free and upper layers of acid emulsions after settling and centrifugation correspondingly contains the compounds which do not participate in the formation of acid emulsions, and the oil phase of the intermediate layers (bottom layer after centrifugation), on the contrary, contains components involved in the formation of oil/acid interface. 


\section{Experimental section}

As an object of this study, the crude oil emulsion produced from the Romashkino field (Tatarstan, Russia) was selected. The free water from the crude oil emulsion was removed by settling. The contents of adsorbed gases, retained water and mechanical impurities (clays, corrosion products and mineral scales) in crude oil emulsion were $12.3 \mathrm{wt} \%, 24.6 \mathrm{wt} \%$ and $2.4 \mathrm{wt} \%$ respectively.

Acidic oil emulsions were prepared on the basis of settled crude oil emulsion using two types of acid formulations: $15 \% \mathrm{HCl}$ solution and $15 \% \mathrm{HCl}$ solution $+5000 \mathrm{ppm}$ of $\mathrm{Fe}$ (III). The acid formulation with $5000 \mathrm{ppm} \mathrm{Fe(III)}$ was prepared by adding $2.5 \mathrm{~mL}$ of $48.3 \mathrm{wt} \%$ solution of $\mathrm{FeCl}_{3} \cdot 6 \mathrm{H}_{2} \mathrm{O}$ in distilled water to $50 \mathrm{~mL}$ of a $15 \%$ solution of hydrochloric acid.

To make an acidic oil emulsion, $50 \mathrm{~mL}$ of the acid formulation of interest was poured into a hermetically sealable glass container. A mark corresponding to the upper boundary of the liquid level was made on the outer wall of the container, and the height of the liquid in the container, $H_{1}$, was measured with a ruler. Then $50 \mathrm{~mL}$ of the emulsion, thoroughly agitated by shaking for $3 \mathrm{~min}$, were added to the vessel. The resulting mixture was stirred in a paddled impeller with a nonmetallic blade for $1 \mathrm{~min}$ at a speed of $500 \mathrm{rpm}$. The level of the lower (aqueous) phase, $\mathrm{H}_{2}$, was measured after 5,10 , and $30 \mathrm{~min}$ of thermostating. After $30 \mathrm{~min}$, the resulting acidic oil emulsion was analyzed. The degree of separation of the acidic oil emulsion into phases $(\Phi, \%)$ was calculated by the formula: $\Phi=\left(H_{2} / H_{1}\right) \times 100 \%$.

The resulting acidic oil emulsions did not separate into layers for $30 \min (\Phi=0)$ but a thin black layer of separated oil appeared on the surface after a day as a result of gravity segregation. This oil layer was drained and examined; hereinafter it is called "free". The remainder of the acidic oil emulsion (after draining the free oil layer separated in a day) was placed in a flask and centrifuged at a speed of $3000 \mathrm{rpm}$ for $1.5 \mathrm{~h}$. Centrifuging resulted in separation into the "upper" (water-free) and "intermediate" (water-containing) layers (Fig. 1). It should be noted that the release of free water from acidic oil emulsions did not occur.

The determination of water content in samples was carried out using a Dean-Stark method (ASTM D4006). The dehydration of samples was carried out using $\mathrm{CaCl}_{2}$.

The oil composition was determined according to standard methods. Gasoline fraction (oil fraction with boiling point temperature $<200{ }^{\circ} \mathrm{C}$ ) was isolated from dewatered oil by the atmospheric distillation method (GOST 2177-99). Asphaltene was precipitated by a 40 -fold volume excess of $n$-heptane, followed by washing with hot

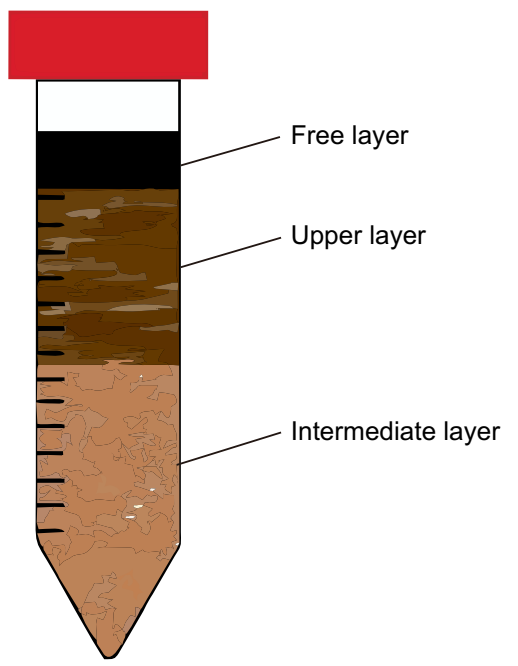

Fig. 1 Separating the acidic oil emulsion into layers after gravity segregation (free layer) and centrifugation (upper and intermediate layers)

$n$-heptane within $8 \mathrm{~h}$ in a Soxhlet apparatus. The deasphalted oil (maltene) was separated into lube oil and resins by liquid-solid adsorption column chromatography on activated wide-pore silica gel ASK with successive elution using $n$-heptane + carbon tetrachloride (3:1) (eluate: lube oil), benzene (eluatenon-polar resin); isopropyl alcohol + benzene (1:1) (eluate- polar resin).

Wax was isolated from the lube oil. A sample of the lube oil was dissolved in a tenfold volume of benzene with heating until the complete dissolution of the sample if necessary. To precipitate wax, a tenfold excess of acetone was added. The resulting mixture was placed in a cooling bath at $-20{ }^{\circ} \mathrm{C}$ for $30 \mathrm{~min}$ and then filtered through a glass filter, which was subsequently rinsed with an ice-cold mixture of benzene and acetone. The wax remaining on the filter was washed into a separate flask with hot benzene. The product was dried until the complete evaporation of the solvents.

The composition of waxes was studied by gas-liquid (GL) chromatography using a Chromatec Kristall-2000 M chromatograph with a flame ionization detector, a DB-1 capillary column of $15 \mathrm{~m}$ in length and $0.32 \mathrm{~mm}$ in inner diameter, and linear temperature programming from 150 to $320{ }^{\circ} \mathrm{C}$ at a rate of $20^{\circ} \mathrm{C} / \mathrm{min}$. The sample size was $1 \mathrm{~mL}$ with a 1:20 dilution in $\mathrm{CCl}_{4}$.

The elemental composition $(\mathrm{C}, \mathrm{H}, \mathrm{N}, \mathrm{S})$ in asphaltenes was performed with Elemental Analyzer EuroEA 3028-HT-OM Eurovector S.p.A. The oxygen (O) and metal $(\mathrm{Me})$ content was determined by difference $100 \%-\left(w_{\mathrm{C}}+w_{\mathrm{H}}+w_{\mathrm{N}}+w_{\mathrm{S}}\right)$, where $w_{\mathrm{C}}, w_{\mathrm{H}}, w_{\mathrm{N}}, w_{\mathrm{S}}$ are the mass content of $\mathrm{C}, \mathrm{H}, \mathrm{N}$, and $\mathrm{S}$. respectively.

Electron spin resonance (EPR) spectra of asphaltenes were recorded on a Radiopan SE/X-2544 EPR spectrometer. 
The concentration of free stable radicals $\left(\mathrm{FSR}, I_{\mathrm{R}}\right.$.) was evaluated by the amplitude of the line width-corrected FSR signal. The concentration of vanadyl $\left(I_{\mathrm{VO}}^{2+}\right)$ complexes was determined from the amplitude of the most intense downfield line next to the single line of the FSR. The measured intensities of the corresponding EPR lines were normalized to the mass of the sample to obtain the values of $\mathrm{R}^{\prime}$ and $\mathrm{VO}^{2+}$ concentrations in relative units.

Benzene, $n$-heptane, carbon tetrachloride, isopropyl alcohol and acetone solvents were $99 \%+$ pure. $\mathrm{HCl}-$ chemical purity, GOST $3118-77$ and $\mathrm{FeCl}_{3} \cdot 6 \mathrm{H}_{2} \mathrm{O}$-purity, GOST 4147-74.

\section{Results and discussion}

\subsection{Composition of free, upper and intermediate layers of acid emulsions with and without Fe(III)}

The prepared acid emulsions were divided into three layers (Table 1): a free layer separated during the day as a result of gravity segregation, the upper and intermediate layers separated during centrifugation (Fig. 1). The free and upper layers are free of water. However, there is water in the intermediate layers. The release of free water from acid oil emulsions after gravity segregation and centrifugal separation did not occur.

As mentioned above, it was assumed that the oil phase of the free and upper layers contains the compounds which do not participate in the formation of acid emulsions, and the oil phase of the intermediate layers, on the contrary, contains components involved in the formation of armor films at the oil/acid interface.

Acid emulsion without $\mathrm{Fe}$ (III) is more stable to separation. After gravity segregation, only $2.8 \mathrm{vol} \%$ of free oil is

Table 1 Volume fraction of layers in emulsions after gravity segregation and centrifugal separation

\begin{tabular}{|c|c|c|c|c|c|}
\hline \multirow[t]{3}{*}{ Sample } & \multirow[t]{3}{*}{ Acid emulsion } & \multicolumn{4}{|c|}{$\begin{array}{l}\text { Volume fraction of layers, \%, separated } \\
\text { as result of }\end{array}$} \\
\hline & & \multirow{2}{*}{$\begin{array}{l}\text { Gravity } \\
\text { segrega- } \\
\text { tion } \\
\text { Free }\end{array}$} & \multicolumn{3}{|c|}{ Centrifugal separation } \\
\hline & & & Upper & Intermediate & Water \\
\hline 1 & $\begin{array}{l}\text { Crude oil emul- } \\
\text { sion + HCl } \\
(15 \%)\end{array}$ & 2.8 & 20.0 & 77.2 & 0.0 \\
\hline 2 & $\begin{array}{l}\text { Crude oil emul- } \\
\text { sion }+\mathrm{HCl} \\
(15 \%)+\mathrm{Fe}(\mathrm{III})\end{array}$ & 7.4 & 29.6 & 63.0 & 0.0 \\
\hline
\end{tabular}

Notes All the crude oil emulsions mentioned in the following were settled to remove free water before use released from it, and after centrifugal separation, the upper layer is $20.0 \mathrm{vol} \%$. In the acid emulsion with the Fe(III), 7.4 $\mathrm{vol} \%$ of free oil is released during gravity segregation, and $29.6 \mathrm{vol} \%$ does in the centrifugation process. The intermediate layer of acid emulsion without $\mathrm{Fe}(\mathrm{III})$ is almost $14 \mathrm{vol} \%$ more than in the acid emulsion with $\mathrm{Fe}$ (III).

The dynamics of oil phase release from acid emulsions with and without $\mathrm{Fe}(\mathrm{III})$ during centrifugal separation was studied (Fig. 2). During centrifugation for $1.5 \mathrm{~h}$ in an acidic emulsion without $\mathrm{Fe}(\mathrm{III})$ a monotonic release of the oil phase occurred. As to acid emulsion with Fe(III), a slightly different trend was observed: first, there was rapid oil phase release-almost $26 \mathrm{vol} \%$ for the first $40 \mathrm{~min}$, and then slow oil release-during remaining $50 \mathrm{~min}$ only about $4 \mathrm{vol} \%$.

The water content in intermediate layers of acid emulsions was defined (Table 2). Water dominates and is 69.0 wt $\%$ and $76.3 \mathrm{wt} \%$ in acid emulsions without and with $\mathrm{Fe}(\mathrm{III})$ correspondingly. In addition, the intermediate layer of acid emulsion with $\mathrm{Fe}$ (III) is characterized by enhanced content of mechanical impurities. Thus, in an acidic emulsion with $\mathrm{Fe}(\mathrm{III})$, the intermediate layer occupies a smaller volume but retains more water. In this regard, it can be assumed that in the presence of $\mathrm{Fe}(\mathrm{III})$, finely dispersed

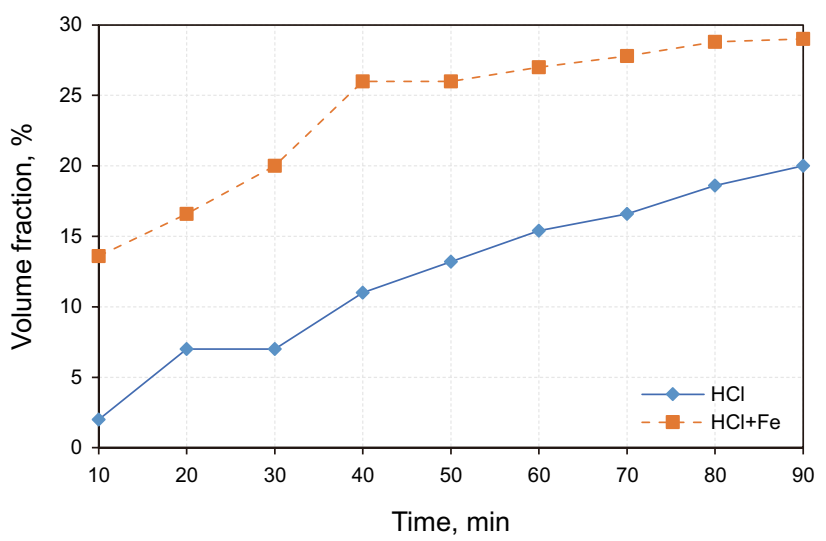

Fig. 2 Dynamics of upper layer release from acid emulsions during centrifugal separation

Table 2 Composition of intermediate layers of acid oil emulsions

\begin{tabular}{lllll}
\hline Sample & Acid emulsion & \multicolumn{2}{l}{ Content, wt \% } \\
\cline { 3 - 4 } & Water & Oil & $\begin{array}{l}\text { Mechani- } \\
\text { cal impuri- } \\
\text { ties }\end{array}$ \\
\hline 1 & $\begin{array}{c}\text { Crude oil emul- } \\
\text { sion + HCl (15\%) } \\
\text { Crude oil emul- } \\
\text { sion }+\mathrm{HCl} \\
(15 \%)+\mathrm{Fe}(\mathrm{III})\end{array}$ & 69.0 & 30.8 & 0.2 \\
\hline
\end{tabular}


emulsion with stronger armor films at the oil/acid interface is formed.

\subsection{Composition of oil phase of different layers of acid emulsions with and without Fe(III)}

The composition of the oil phase of different layers of acid emulsions (Table 3) was studied and compared.

As can been seen from Table 3, the composition of the free and upper layers of acid emulsions without Fe(III) is almost the same and coincides with the composition of the oil phase of initial crude oil emulsion taken for preparation of the acid emulsions, except for the waxes. In these layers, the content of waxes is noticeably lower. Perhaps, this is due to a change in the solvent ability of oil in relation to waxes in the presence of acid. The free and upper layers of acid emulsions with $\mathrm{Fe}$ (III) are characterized by reduced content of non-polar resins compared with initial crude oil emulsion. In the presence of $\mathrm{Fe}(\mathrm{III})$, waxes are distributed evenly between free and upper layers. Intermediate layers of both emulsions are characterized by reduced content of non-polar resins and enhanced content of asphaltenes. In the presence of $\mathrm{Fe}(\mathrm{III})$ the content of asphaltenes at the interface almost doubles. Thus, the oil/acid interfaces are enriched with asphaltenes and depleted by non-polar resins.

It is well known that asphaltenes are defined as the heaviest components of petroleum fluids that are insoluble in light $n$-alkanes such as $n$-pentane or $n$-heptane but soluble in aromatics such as benzene or toluene. These polydisperse molecules consist mostly of polynuclear aromatics with different proportions of aliphatic and alicyclic moieties and small amounts of heteroatoms (such as oxygen, nitrogen and sulfur) and heavy metals (such as vanadium and nickel which occur in porphyrin structures). In petroleum the asphaltenes are in the form of supramolecular assembles of different hierarchies (nanoaggregates, clusters, flocs) (Mullins 2010). The structure and composition of resins are similar to ones of asphaltenes but resins do not aggregate. And this is their main difference from asphaltenes. It is believed that the resins in the oil are in the molecular state, and do not flocculate in adding the low molecular weight $n$-alkanes. However, as it was shown by Rietjens et al. (2001), in acidic conditions, the picture can change. It was found that in the presence of $\mathrm{HCl}$, the aggregation of nonpolar oil components occurred as result of their protonation. In the presence of $\mathrm{Fe}(\mathrm{III})$ this process was enhanced. The resulting aggregates were similar in size to flocculated asphaltenes (Rietjens 1997). Thus, it can be assumed that in the acidic emulsion as result of redox reactions the protonation of non-polar resins and their subsequent flocculation are possible. This makes non-polar resins similar to asphaltenes in acidic condition. That's why we observe a decrease in the content of non-polar resins and an increase in the content of asphaltenes in the intermediate layers (Table 3). In the presence of ferric cations there is protonation not only of non-polar resins, but also components of the lube oils: in the intermediate layer of the acid emulsion with $\mathrm{Fe}(\mathrm{III})$, the content of the lube oils is significantly reduced. Asphaltenes and flocculated material which results from aggregation of protonated non-polar oil components (non-polar resins and lube oils) concentrate at the acid/oil interface and stabilize the emulsion.

It is interesting to compare the composition of waxes and asphaltenes isolated from oil phase of different layers of acid emulsions.

\subsection{Hydrocarbon composition of waxes in different layers of acid emulsions with and without Fe(III)}

Waxes of different emulsion layers were investigated by gas-liquid (GL) chromatography (Fig. 3). There are $n$-alkanes with the number of carbon atoms from $\mathrm{C}_{11}$ to $\mathrm{C}_{36}$ in waxes. The waxes of different layers of acid emulsion without $\mathrm{Fe}$ (III) are characterized by the same distribution of $n$-alkanes - the maximum is in $\mathrm{C}_{25}-\mathrm{C}_{26}$. The distribution of $n$-alkanes in the upper layer of acid emulsion with $\mathrm{Fe}$ (III) is much the same as for emulsion without

Table 3 Composition of the oil phase of different layers of acid emulsions

\begin{tabular}{|c|c|c|c|c|c|c|}
\hline \multirow[t]{3}{*}{ Sample } & \multirow[t]{3}{*}{ Layer } & \multicolumn{5}{|l|}{ Content, wt \% } \\
\hline & & \multirow{2}{*}{$\begin{array}{l}\text { Lube oil/Content of } \\
\text { waxes in them }\end{array}$} & \multicolumn{2}{|l|}{ Resin } & \multirow[t]{2}{*}{ Asphaltene } & \multirow{2}{*}{$\begin{array}{l}\text { Resin-asphal- } \\
\text { tene compo- } \\
\text { nents }\end{array}$} \\
\hline & & & Non-polar & Polar & & \\
\hline Crude oil emulsion & Oil & $74.4 / 9.1$ & 17.0 & 4.1 & 4.5 & 25.6 \\
\hline \multirow[t]{3}{*}{ Crude oil emulsion $+\mathrm{HCl}(15 \%)$} & Free & $72.7 / 6.3$ & 17.2 & 5.4 & 4.7 & 27.3 \\
\hline & Upper & $75.9 / 6.4$ & 15.3 & 4.6 & 4.2 & 24.1 \\
\hline & Intermediate & $75.9 / 6.9$ & 13.5 & 4.8 & 5.8 & 24.1 \\
\hline \multirow[t]{3}{*}{ Crude oil emulsion $+\mathrm{HCl}(15 \%)+\mathrm{Fe}(\mathrm{III})$} & Free & $75.1 / 10.6$ & 14.8 & 5.5 & 4.6 & 24.9 \\
\hline & Upper & $77.4 / 7.8$ & 14.3 & 3.5 & 4.8 & 22.6 \\
\hline & Intermediate & $72.8 / 9.3$ & 13.4 & 4.3 & 9.5 & 27.2 \\
\hline
\end{tabular}




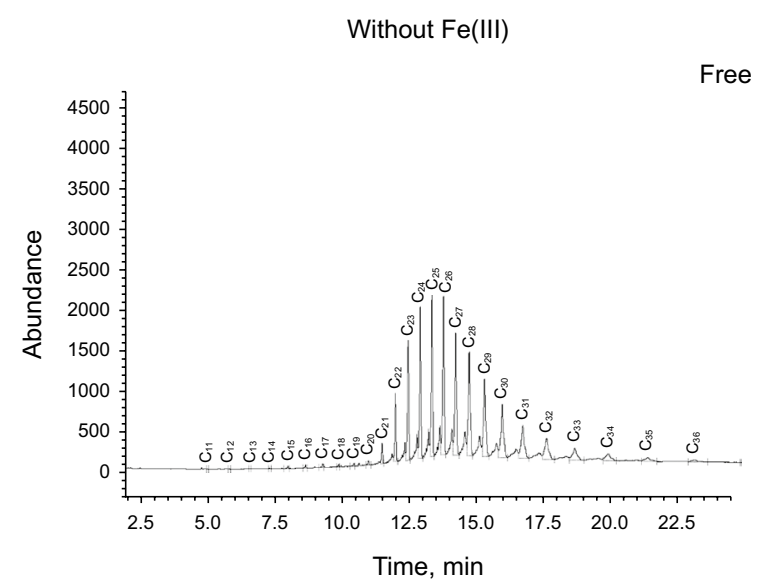

With $\mathrm{Fe}(\mathrm{III})$

Free layer
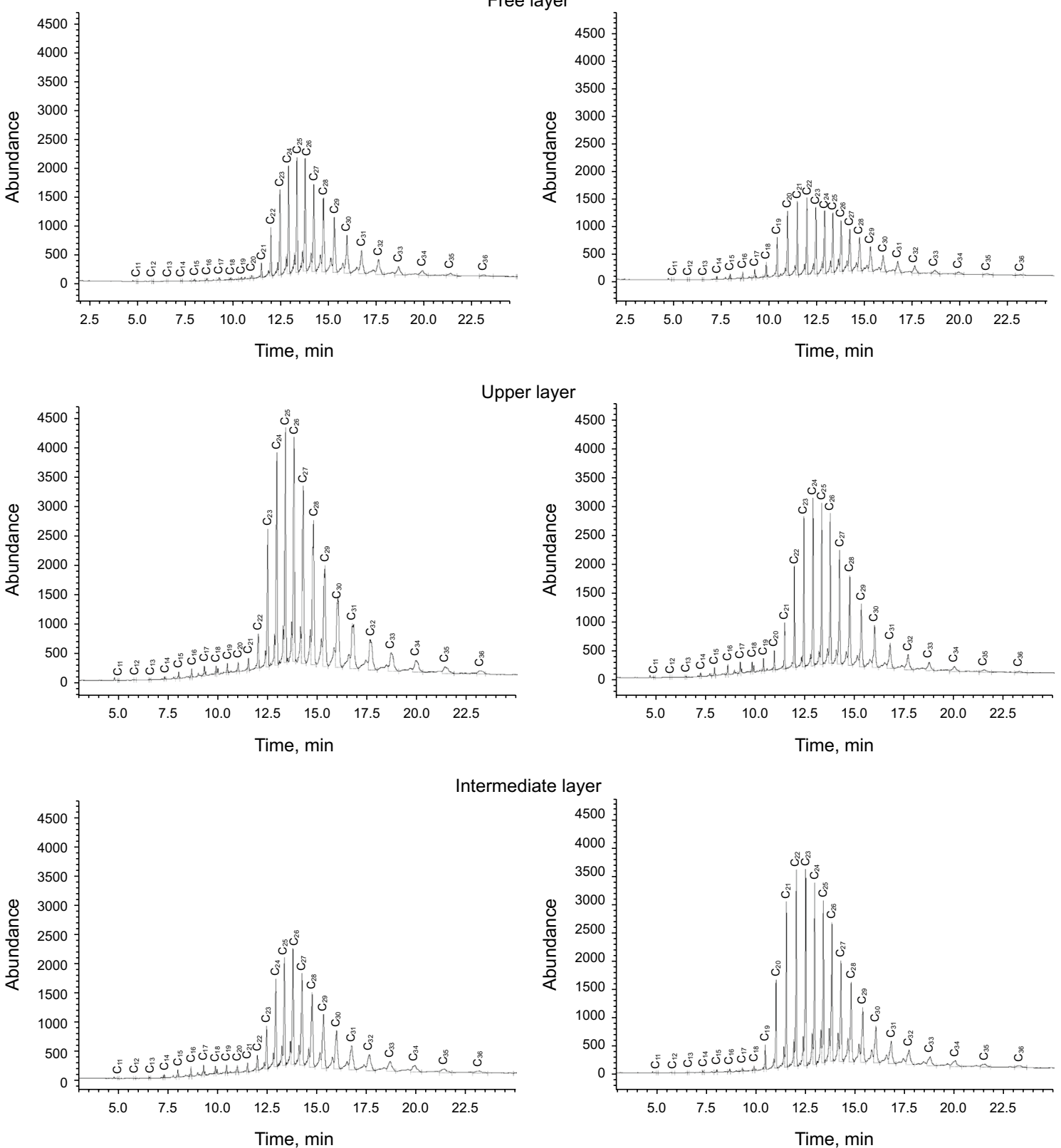

Fig. 3 GL chromatogram of waxes of oil phases from different layers of acid emulsions

$\mathrm{Fe}$ (III) - the maximum is in $\mathrm{C}_{24}-\mathrm{C}_{25}$. However, in waxes from the free and intermediate layers of the acid emulsion with $\mathrm{Fe}$ (III) $n$-alkanes with lower molecular weight $\left(\mathrm{C}_{20}-\mathrm{C}_{24}\right)$ dominate. Thus, it can be assumed that in the presence of $\mathrm{Fe}$ (III) the paraffin hydrocarbons redistribute between the different layers of the acid emulsion not quantitatively (Table 3) but qualitatively (Fig. 3).

\subsection{Composition of asphaltenes in different layers of acid emulsions with and without Fe(III)}

The composition of asphaltenes was characterized by elemental composition (Table 4) and content of paramagnetic particles according to electron paramagnetic resonance (EPR) spectroscopy (Table 5). 
Table 4 Elemental composition of asphaltenes of different layers of acid emulsions

\begin{tabular}{|c|c|c|c|c|c|c|c|}
\hline \multirow[t]{2}{*}{ Sample } & \multirow[t]{2}{*}{ Layer } & \multicolumn{5}{|c|}{ Elemental composition, wt $\%$} & \multirow[t]{2}{*}{$\mathrm{C} / \mathrm{H}$ mass ratio } \\
\hline & & $\mathrm{C}$ & $\mathrm{H}$ & $\mathrm{N}$ & $\mathrm{S}$ & $\begin{array}{l}\mathrm{O}+\mathrm{Me} \text { (by } \\
\text { difference) }\end{array}$ & \\
\hline Crude oil emulsion & Oil & 81.76 & 7.38 & 2.07 & 2.52 & 6.27 & 11.1 \\
\hline \multirow[t]{3}{*}{ Crude oil emulsion $+\mathrm{HCl}(15 \%)$} & Free & 82.70 & 7.32 & 2.49 & 0.75 & 6.74 & 11.3 \\
\hline & Upper & 81.06 & 7.18 & 2.06 & 0.83 & 8.87 & 11.3 \\
\hline & Intermediate & 74.59 & 6.78 & 1.93 & 2.57 & 14.13 & 11.0 \\
\hline \multirow[t]{3}{*}{ Crude oil emulsion $+\mathrm{HCl}(15 \%)+\mathrm{Fe}(\mathrm{III})$} & Free & 82.48 & 7.41 & 2.04 & 1.98 & 6.09 & 11.1 \\
\hline & Upper & 79.40 & 7.61 & 1.89 & 3.95 & 7.15 & 10.4 \\
\hline & Intermediate & 75.81 & 6.21 & 1.74 & 3.01 & 13.23 & 12.2 \\
\hline
\end{tabular}

Table 5 EPR spectroscopy data of asphaltenes of acid emulsions (in relative units)

\begin{tabular}{|c|c|c|c|c|}
\hline Sample & Layer & $\begin{array}{l}\text { Concentration of free stable } \\
\text { radicals, } \lg I_{\mathrm{R}} \text {. }\end{array}$ & $\begin{array}{l}\text { Concentration of vanadyl } \\
\text { complexes, } \lg I_{\mathrm{VO}}^{2+}\end{array}$ & $\operatorname{Lg}\left(I_{\mathrm{R}} \cdot / I_{\mathrm{VO}}^{2+}\right)$ \\
\hline Crude oil emulsion & Oil & 2.3 & 1.2 & 1.1 \\
\hline \multirow[t]{3}{*}{ Crude oil emulsion $+\mathrm{HCl}(15 \%)$} & Free & 2.3 & 1.1 & 1.2 \\
\hline & Upper & 2.4 & 1.2 & 1.2 \\
\hline & Intermediate & 2.1 & 1.0 & 1.1 \\
\hline \multirow[t]{3}{*}{ Crude oil emulsion $+\mathrm{HCl}(15 \%)+\mathrm{Fe}(\mathrm{III})$} & Free & 2.0 & 1.0 & 1.0 \\
\hline & Upper & 0.2 & 0.1 & 0.1 \\
\hline & Intermediate & - & - & - \\
\hline
\end{tabular}

In asphaltenes the contents of $\mathrm{C}, \mathrm{H}, \mathrm{N}, \mathrm{S}$, and $\mathrm{O}$ and metals (Me) (by difference) were determined (Table 4). In asphaltenes from the initial crude oil emulsion the contents of $\mathrm{C}, \mathrm{H}, \mathrm{N}, \mathrm{S}$, and $\mathrm{O}+\mathrm{ME}$ are $81.8 \%, 7.4 \%, 2.1 \%$, $2.5 \%$, and $6.3 \%$, respectively; the mass ratio of $\mathrm{C}$ to $\mathrm{H}$ is 11.1. As can be seen from Table 4, asphaltenes from the free and upper layers of the acid emulsion without Fe(III) are almost the same by elemental composition, depleted in sulfur and characterized by almost the same $\mathrm{C} / \mathrm{H}$ mass ratio in comparison with asphaltene from the initial crude oil emulsion. Large part of sulfur-containing compounds (2.6\%) and compounds, containing $\mathrm{O}$ and $\mathrm{Me}(14.1 \%)$, concentrates in asphaltenes of the intermediate layer. Thus, it can be noted that in the acid emulsion without $\mathrm{Fe}$ (III) at the oil/acid interface, asphaltenes with a high content of sulfur, oxygen and metals are concentrated.

In an acidic emulsion with $\mathrm{Fe}(\mathrm{III})$, the distribution of elements is more even, but even here it can be seen that asphaltenes with a high content of $\mathrm{O}$ and $\mathrm{Me}$ are concentrated at the interface. In addition, it can be observed that in the acid emulsion with $\mathrm{Fe}(\mathrm{III})$ asphaltenes of the upper layer are enriched with hydrogen ( $\mathrm{C} / \mathrm{H}$ mass ratio: 10.4), and the asphaltenes of the intermediate layer are depleted with hydrogen $(\mathrm{C} / \mathrm{H}$ mass ratio: 12.2$)$ in comparison with the corresponding asphaltenes from the acid emulsion without $\mathrm{Fe}(\mathrm{III})$ and from initial crude oil emulsion.

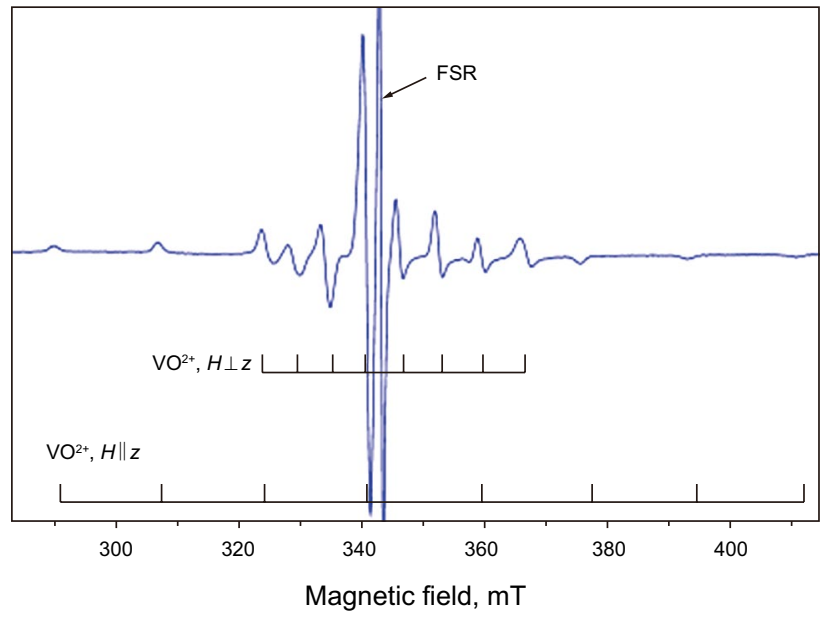

Fig. 4 EPR spectrum of asphaltene

In order to study the distribution of paramagnetic ferric cations in the emulsions and their interaction with intrinsic paramagnetic particles of oil (FSR and vanadyl ions), asphaltenes of different emulsion layers were studied by EPR spectroscopy. It is well known that petroleum asphaltenes exhibit significant paramagnetism, which is expressed through two types of EPR signals (Fig. 4): a symmetric signal of free stable radical (FSR) $(g=2.003)$ 
and a multicomponent hyperfine structure (two groups of lines, eight in each, corresponding to the complexes of tetravalent vanadium, the axis of symmetry of which is oriented parallel $\left(H \|_{z}\right)$ and perpendicular $(H \perp z)$ to the direction of the external magnetic field $H$ ) due to paramagnetic $\mathrm{VO}^{2+}$ ions involved mainly in porphyrin complexes (Yen et al. 1962; Unger and Andreeva 1995; Tayeb et al. 2015). It is considered that FSRs in asphaltenes arise due to the delocalized $\pi$-electron of polycondensed aromatic core. The concentration of FSRs in asphaltenes is usually associated with their aromaticity (Yen et al. 1962). Vanadyl porphyrins bear an unpaired electron localized in the surroundings of $\mathrm{VO}$ bond. The content of $\mathrm{VO}^{2+}$ is directly related to the vanadium content in petroleum and depends on the age and conditions of petroleum reservoir formation (Tayeb et al. 2015). Vanadyl porphyrins play an important role in asphaltene aggregation (Dechaine and Gray 2010, 2011).

The composition and content of paramagnetic particles in asphaltenes of different layers of both emulsions were studied.

Asphaltenes from free and upper layers of the acid emulsion without $\mathrm{Fe}$ (III) are similar to asphaltenes from the initial crude oil emulsion by yield (Table 3 ) and the content of the FSRs and vanadyl ions (Table 5). A minor decrease in the concentration of both FSRs and vanadyl ions occurs in the intermediate layer in saving the ratio of $\lg \left(I_{\mathrm{R}} \cdot / I_{\mathrm{VO}}^{2+}\right)$. This and an increased content of asphaltenes in the intermediate layer (Table 3) indicate the appearance of diamagnetic impurities in the asphaltenes. For example, it has previously been shown (Ganeeva et al. 2011) that the co-precipitation of waxes with asphaltenes leads to a proportional decrease in the concentration of FSRs and vanadyl ions in asphaltenes. Taking into account the decreased amount of no-polar resins (Table 3) and enhanced amount of $\mathrm{S}$ and $\mathrm{O}$ and $\mathrm{Me}$ (Table 4) it can be assumed that part of diamagnetic particles in asphaltenes are flocculated material of protonated nonpolar resins and sulfur- and oxygen-containing compounds.

The effect of high-spin ferric cations on the paramagnetic composition of asphaltenes of different layers of acid emulsion more pronounced. Indeed, in all EPR spectra, together with the signals from FSRs and vanadyl ions in the interval 341-345 $\mathrm{T}$, there are signals from ferric cations with $g$-factors are 2.0 and 4.2 (Fig. 5, left). It has been suggested (Antipenko et al. 1994) that wide line with $g$-factor of 2.0 is due to $\mathrm{Fe}$ (III) in loosely bound octahedral complexes with a small axial deformation of cubic symmetry. In addition, absorption in this region may be due to the exchange interactions between Fe ion clusters. Absorption in the region of $g$-factor of 4.2 is due to Fe(III) bound into octahedral or tetrahedral complexes with high rhombic symmetry.

In our case, in asphaltenes from free, upper and intermediate layers the ratios of ferric cations with $g$-factor of 2.0 are 2:8:9, and ones of ferric cations with $g$-factor of 4.2 do $1: 2: 4$ correspondingly.

Asphaltenes of the free layer are characterized by a low content of ferric cations and reduced content of intrinsic paramagnetic particles (FSR and vanadyl ions) in saving the ratio of $\lg \left(I_{\mathrm{R}} \cdot / I_{\mathrm{VO}}^{2+}\right)$ (Fig. 5, Table 5). In the asphaltenes of the upper layer, the content of ferric cations increases and only the traces of intrinsic paramagnetic particles are recorded. In this case, judging by the low value of $\lg \left(I_{\mathrm{R}} \cdot / I_{\mathrm{VO}}^{2+}\right)$, the content of the FSRs decreases to a greater extent. The most ferric cations is found in the asphaltenes of the intermediate layer of acid emulsion with Fe(III). At that, the intensity of the lines due to free stable radicals and vanadyl ions dramatically decreases (Fig. 5, right). Taking into account that amount of asphaltenes in free and upper layers is almost the same as in initial crude oil, the decreased content of FSRs and vanadyl ions in them can be due to appearance in asphaltenes of some Fe(III)-based complexes formed as a result of binding some amount of ferric cations, transferred to the oil phase from aqueous, with polar groups of asphaltenes. Previously it was reported (Antipenko et al. 1994) that under interaction of $\mathrm{FeCl}_{3}$ with asphaltenes, polycondensed aromatic hydrocarbons, carboxylic acids the formation of insoluble in aliphatic hydrocarbons complexes occurred and was shown that the centers of localization of ferric cations were molecular moieties containing heteroatoms, free stable radicals, and vanadyl ions.

Almost two times higher content of asphaltenes in the intermediate layer (Table 3) along with increased content of ferric cations and dramatically decreased number of paramagnetic particles of FSRs and vanadyl ions can be explained by the appearance in the asphaltenes of a large number of $\mathrm{Fe}$ (III)-based complexes. Possible reactions for the formation of divalent metal-based complexes in emulsions were described by Brandal et al. (2004), Brandal and Sjoblom (2005) and in our case we can also assume several stages of $\mathrm{Fe}(\mathrm{III})$-based complex formation:

(1) Diffusion of Fe(III) into the interface acid/oil.

(2) Electrostatic attraction between the ferric cations and polar groups of resin-asphaltene compounds across the interface.

(3) Formation of stable Fe(III)-based complexes as result of donor-acceptor interactions (Fe(III) as electron acceptor, polar groups in resin-asphaltene compounds as electron donors).

These complexes along with the flocculated material of protonated non-polar oil components concentrate at the acid/ oil interface and contribute to the formation of armor films which enhance the emulsion stability.

Apropos, the observed predominance of low molecular weight paraffin hydrocarbons in the upper and intermediate 

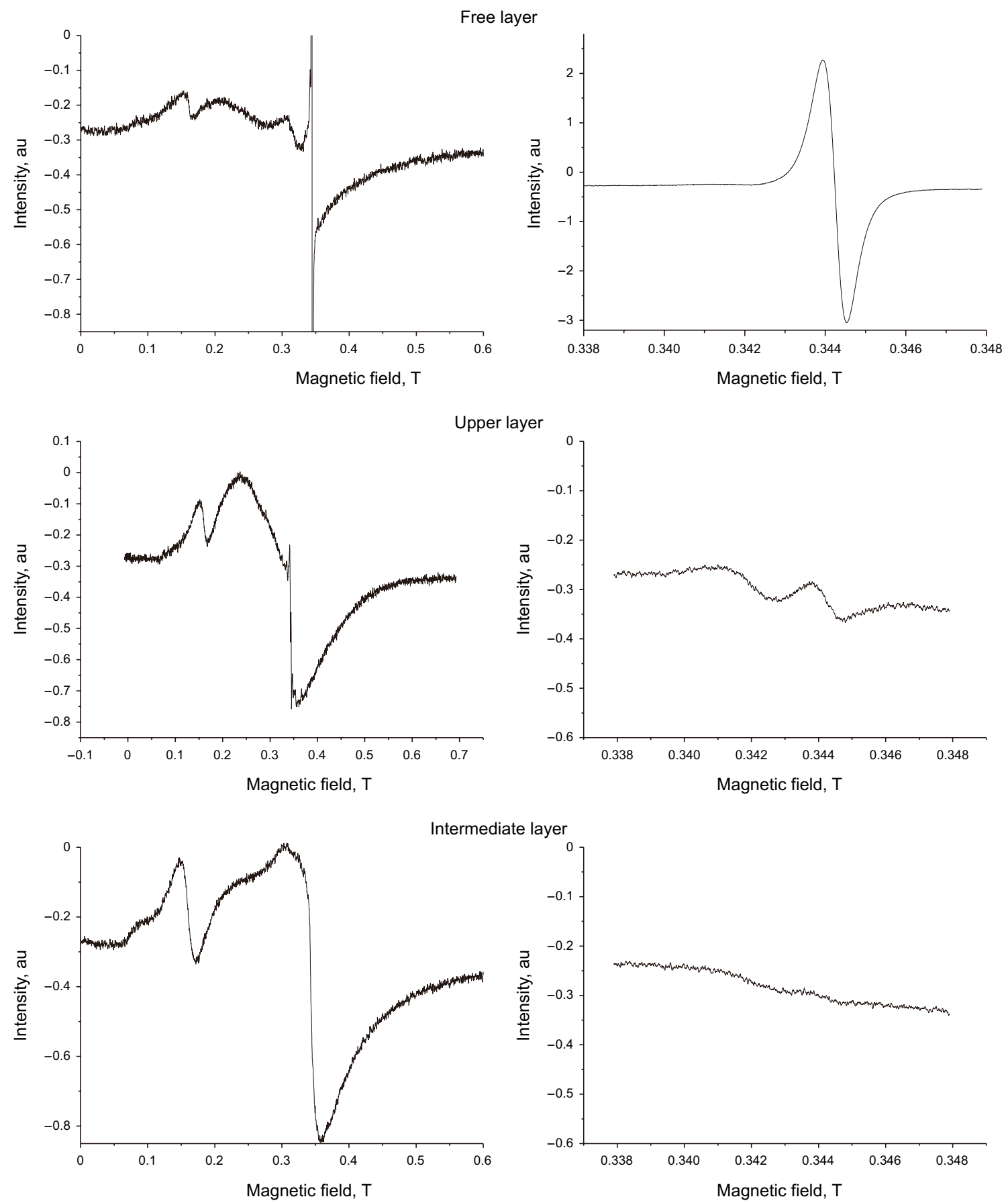

Fig. 5 EPR spectra of asphaltenes of free, upper and intermediate layers of acid emulsion with Fe(III): on the left-broad band of magnetic field $0-0.6 \mathrm{~T}$, on the right-narrow band of magnetic field $0.338-0.348 \mathrm{~T}$, where signals from FSR and $\mathrm{VO}^{2+}$ have to appear 
layers of acid emulsion with $\mathrm{Fe}$ (III) (Fig. 3) can be explained by their capture by the Fe(III)-based complexes.

\section{Conclusions}

The quantitative and qualitative redistributions of asphaltenes and waxes in acid emulsions were investigated by mixing crude oil emulsion with $15 \%$ hydrochloric acid solutions with and without Fe(III). The experimental results show that the acid emulsion with $\mathrm{Fe}(\mathrm{III})$ is more easily stratified in comparison with the acid emulsion without Fe(III), but the water remaining in it is more strongly retained. The acid/oil interface is enriched with asphaltenes with a high content of sulfur, oxygen and metals, and depleted by non-polar resins. It is assumed that the stabilization of acid emulsions occurs when the strong-polar asphaltenes and flocculated material of protonated non-polar resins are concentrated at the acid/oil interface. In the presence of $\mathrm{Fe}(\mathrm{III})$, stable organometallic complexes are composed of ferric cations and polar groups of asphaltenes. These complexes along with the flocculated material of protonated non-polar oil components are concentrated at the acid/oil interface and contribute to the formation of armor films which enhance the emulsion stability. It is possible that these organometallic complexes have the ability to capture low weight molecular alkanes, that may also have an effect on the stabilization of emulsions.

The results obtained allow to describe in more detail the processes at the oil/acid interface depending on the presence or absence of ferric ions and oil composition. This understanding enables to justify the selection of acid compositions and technological solutions, which will decrease a possibility of the emulsion and sludge formation on the contact with crude oil.

Acknowledgements The authors gratefully acknowledge the CSF-SAC FRC KSC RAS for providing necessary facilities to carry out this work.

Open Access This article is licensed under a Creative Commons Attribution 4.0 International License, which permits use, sharing, adaptation, distribution and reproduction in any medium or format, as long as you give appropriate credit to the original author(s) and the source, provide a link to the Creative Commons licence, and indicate if changes were made. The images or other third party material in this article are included in the article's Creative Commons licence, unless indicated otherwise in a credit line to the material. If material is not included in the article's Creative Commons licence and your intended use is not permitted by statutory regulation or exceeds the permitted use, you will need to obtain permission directly from the copyright holder. To view a copy of this licence, visit http://creativecommons.org/licenses/by/4.0/.

\section{References}

Abdel-Raouf ME. Factors affecting the stability of crude oil emulsions. In: Abdel-Raouf ME, editor. Crude oil emulsions-composition stability and characterization. InTech: Groatia; 2012. p. 183-201. https://doi.org/10.5772/35018.

Antipenko VR, Pevneva GS, Zemtseva LI. Composition of products of interaction of components of residual oil fractions with ferric chloride. Neftekhimiya. 1994;34:82-94.

Brandal Ø, Sjöblom J, Øye G. Interfacial behaviour of naphthenic acids and multivalent cations in systems with oil and water, part I: a pendant drop study of interactions between $n$-dodecyl benzoic acid and divalent cations. J Disp Sci Technol. 2004;25:367-74. https://doi.org/10.1081/DIS-120037687.

Brandal $\varnothing$, Sjoblom J. Interfacial behavior of naphthenic acids and multivalent cations in systems with oil and water. II: formation and stability of metal naphthenate films at oil-water interfaces. J Disp Sci Technol. 2005;26:53-8. https://doi.org/10.1081/DIS200040145.

Dechaine GP, Gray MR. Chemistry and association of vanadium compounds in heavy oil and bitumen, and implications for their selective removal. Energy Fuels. 2010;24:2795-808. https://doi. org/10.1021/ef100173j.

Dechaine GP, Gray MR. Membrane diffusion measurements do not detect exchange between asphaltene aggregates and solution phase. Energy Fuels. 2011;25(2):509-23. https://doi. org/10.1021/ef101050a.

Fredd CN, Fogler HS. Alternative stimulation fluids and their impact on carbonate acidizing. SPE J. 1998;13:34-41. https://doi. org/10.2118/31074-MS.

Ganeeva YuM, Yusupova TN, Romanov GV. Asphaltene nanoaggregates: structure, phase transitions and effect on petroleum systems. Russ Chem Rev. 2011;80:993-1008. https://doi. org/10.1070/rc2011v080n10abeh004174.

Gao S, Moran K, Xu Z, Masliyah J. Role of naphthenic acids in stabilizing water-in-diluted model oil emulsions. J Phys Chem B. 2010;114(23):7710-8. https://doi.org/10.1021/jp910855q.

Hadabi IA, Sasaki K, Sugai Yu. Effect of kaolinite on water-in-oil emulsion formed by steam injection during tertiary oil recovery: a case study of an Omani heavy oil sandstone reservoir with high kaolinite sludge content. Energy Fuels. 2016;30:10917-24. https://doi.org/10.1021/acs.energyfuels.6b01822.

Khadim MA, Sarbar MA. Role of asphaltene and resin in oil field emulsions. J Pet Sci Eng. 1999;23:213-21. https://doi. org/10.1016/s0920-4105(99)00024-8.

McLean JD, Kilpatrick PK. Effects of asphaltene aggregation in model heptane-toluene mixtures on stability of water-in-oil emulsions. J Colloid Interface Sci. 1997;196(1):23-34. https:// doi.org/10.1006/jcis.1997.5177.

Muller H, Pauchard VO, Hajji AA. Role of naphthenic acids in emulsion tightness for a low total acid number (TAN)/high asphaltenes oil: characterization of the interfacial chemistry. Energy Fuels. 2009;23:1280-8. https://doi.org/10.1021/ef800 $620 \mathrm{e}$.

Mullins OC. The modified Yen model. Energy Fuels. 2010;24(4):2179207. https://doi.org/10.1021/ef900975e.

O’Neil B, Maley D, Lalchan C. Prevention of acid-induced asphaltene precipitation: a comparison of anionic vs. cationic surfactants. J Can Pet Technol. 2015;1:49-62. https://doi.org/10.2118/16408 7-pa.

Pereira RCL, Carvalho RM, Couto BC, de Oliveira MCK, Eberlin MN, Vaz BG. Waxy crude oil emulsion gel: chemical characterization of emulsified phase extract components. Energy Fuels. 2014;28:7352-8. https://doi.org/10.1021/ef500962e. 
Poindexter MK, Marsh SC. Inorganic solid content governs waterin-crude oil emulsion stability predictions. Energy Fuels. 2009;23:1258-68. https://doi.org/10.1021/ef800652n.

Qjao P, Harbottle D, Tchoukov P, Wang X, Xu Z. Asphaltene subfractions responsible for stabilizing water-in-crude oil emulsions Part 3. Effect of solvent aromaticity. Energy Fuels. 2017;31:9179-87. https://doi.org/10.1021/acs.energyfuels.7b01387.

Rietjens M. Sense and non-sense about acid-induced sludge. In: SPE European formation damage conference, Hague, The Netherlands, June 2-3, 1997. https://doi.org/10.2118/38163-MS.

Rietjens M, Haasterecht MV. Phase transport of $\mathrm{HCl}, \mathrm{HFeCl}_{4}$, water, and crude oil components in acid-crude oil systems. J Colloid Interface Sci. 2003;268:489-500. https://doi.org/10.1016/j. jcis.2003.08.030.

Rietjens M, Nieuwpoort M. An analysis of crude oil-acid reaction products by size-exclusion chromatography. Fuel. 2001;80:33-40. https://doi.org/10.1016/S0016-2361(00)00073-9.

Rocha JA, Baydak EN, Yarranton HW. What fraction of the asphaltenes stabilizes water-in-bitumen emulsions? Energy Fuels. 2018;32:1440-50. https://doi.org/10.1021/acs.energyfuels.7b035 32.

Rojas-Ruiz FA, Orrego-Ruiz JA. Finding a relationship between the composition and the emulsifying character of asphaltenes through FTICR-MS. CT\&F. 2018;8:45-52. https://doi.org/10.29047 /01225383.90.

Sedghi M, Goual L. Role of resins on asphaltene stability. Energy Fuels. 2009;24(4):2275-80. https://doi.org/10.1021/ef9009235.

Shirazi MM, Ayatollahi S, Ghotbi C. Damage evaluation of acid-oil emulsion and asphaltic sludge formation caused by acidizing of asphaltenic oil reservoir. J Pet Sci Eng. 2019;174:880-90. https ://doi.org/10.1016/j.petrol.2018.11.051.

Spiecker PM, Gawrys KL, Trail CB, Kilpatrick PK. Effects of petroleum resins on asphaltene aggregation and water-in-oil emulsion formation. Colloids Surf A. 2003;220:9-27. https://doi. org/10.1016/s0927-7757(03)00079-7.

Sullivan AP, Kilpatrick PK. The effects of inorganic solid particles on water and crude oil emulsion stability. Ind Eng Chem Res. 2002;41:3389-404. https://doi.org/10.1021/ie010927n.

Tayeb KB, Delpoux O, Barbier J, Marques J, Verstraete J, Vezin H. Applications of pulsed electron paramagnetic resonance spectroscopy to the identification of vanadyl complexes in asphaltene molecules. Part 1: influence of the origin of the feed. Energy Fuels. 2015;29:4608-15. https://doi.org/10.1021/acs.energyfuel s.5b00733.

Umar AA, Mohd Saaid IB, Sulaimon AA, Bint R, Pilus M. A review of petroleum emulsions and recent progress on water-in-crude oil emulsions stabilized by natural surfactants and solids. J Pet Sci Eng. 2018;165:673-90. https://doi.org/10.1016/j.petro 1.2018.03.014.

Unger FG, Andreeva LN. Fundamental aspects of the oil chemistry. Nature of the resins and asphaltenes. Novosibirsk: Nauka. Sibirskay izdatelskay firma RAN; 1995.

Yang F, Tchoukov P, Pensini E, Dabros T, Czamecki J, Masliyah J et al. Asphaltene subfractions responsible for stabilizing water-incrude oil emulsions. Part 1: interfacial behaviors. Energy Fuels. 2014;28:6897-904. https://doi.org/10.1021/ef501826g.

Yang F, Tchoukov P, Dettman H, Teklebrhan RB, Liu L, Dabros T et al. Asphaltene subfractions responsible for stabilizing water-in-crude oil emulsions. Part 2: molecular representations and molecular dynamics simulations. Energy Fuels. 2015;29:4783-94. https:// doi.org/10.1021/acs.energyfuels.5b00657.

Yen TF, Erdman JG, Saraceno AJ. Investigation of structure of petroleum asphaltenes and related substances by electron spin resonance. Anal Chem. 1962;34:694-700. 